Federal Reserve Bank of Minneapolis

Research Department Staff Report 238

Revised June 1999

\title{
Efficient Allocations with Hidden Income and Hidden Storage*
}

\author{
Harold L. Cole
}

Federal Reserve Bank of Minneapolis

Narayana R. Kocherlakota

University of Minnesota

and Federal Reserve Bank of Minneapolis

\begin{abstract}
We consider an environment in which individuals receive income shocks that are unobservable to others and can privately store resources. We provide a simple characterization of the efficient allocation in cases in which the rate of return on storage is sufficiently high or, alternatively, in which the worst possible outcome is sufficiently dire. We show that, unlike in environments without unobservable storage, the symmetric efficient allocation is decentralizable through a competitive asset market in which individuals trade risk-free bonds among themselves.
\end{abstract}

*This paper was previously circulated under the title, "A Microfoundation for Incomplete Security Markets," Research Department Working Paper 577, Federal Reserve Bank of Minneapolis. We thank Christophe Chamley, V.V. Chari, Janice Eberly, Ed Green, John Heaton, Tim and Pat Kehoe, Robert Lucas, Lee Ohanian, and Chris Phelan for comments and suggestions. See the Minneapolis Fed's home page on the World Wide Web at http://woodrow.mpls.frb.fed.us for further revisions, as well as other papers. The views expressed herein are the those of the authors and not necessarily those of the Federal Reserve Bank of Minneapolis or the Federal Reserve System. 


\section{Introduction}

In this paper, we consider an environment in which individuals have random income, and can accumulate assets through a storage technology. Their income realizations and their asset position are private information. Given these informational frictions, we provide a simple characterization of the efficient allocation in cases in which the rate of return on storage is sufficiently high or, alternatively, in which the worst possible outcome is sufficiently dire. We show that the symmetric efficient allocation is decentralizable through a competitive asset market in which individuals trade risk-free bonds among themselves.

There is a large prior literature which examines the characteristics of efficient risksharing in dynamic settings in the presence of private information. ${ }^{1}$ Unlike our paper, this literature generally finds that efficient allocations do not coincide with the equilibrium allocations of any economy with a competitive bond market (see Atkeson and Lucas (1992) in particular). The key difference between our paper and these preceding ones is that the earlier literature assumes either that agents cannot accumulate resources over time, or that, if they can, this accumulation is observable. In contrast, we assume that both agents' incomes and their stored resources are private information. It is this combination of assumptions that leads to our result.

Our findings are reminiscent of Allen's (1985). He considers a dynamic principal-agent relationship in which the agent is risk averse and has hidden stochastic income. The agent is able to secretly borrow and lend at the same interest rate that the principal faces. The ability to secretly borrow and lend means that the agent will, regardless of his true history, claim to have the history of income realizations that delivers the transfer sequence with the highest net present value (NPV). Hence, it is not incentive-compatible for the NPV of the principal's payments to the agent to depend on the agent's history of income realizations. It follows that there is only one incentive-compatible consumption allocation and it is the same as the one in which the agent borrows and lends on his own without receiving transfers from the principal.

\footnotetext{
${ }^{1}$ Contributions to the literature on hidden income include Townsend (1982), Green (1987), Taub (1990), Green and Oh (1991), Atkeson and Lucas (1992), Aiyagari and Alvarez (1995), and Wang (1995). Contributions to the literature on hidden effort include Thomas and Worrall (1990), Phelan and Townsend (1991), Atkeson and Lucas (1995), and Phelan (1995)
} 
In our paper, the agents are allowed to store secretly (essentially, save) at a fixed rate of return, but not borrow. Because agents cannot borrow secretly, the incentive-constraints in our setting are looser than the ones in Allen's model. It is easy to show there is a finitedimensional set of incentive-compatible allocations, not just one incentive-compatible allocation as in Allen's model. The contribution of our paper is to show that the symmetric efficient element of this large set of incentive-compatible allocations is, under some conditions, equivalent to an allocation in which agents borrow and lend at a risk-free rate.

For a two-period setting, the intuition behind our results works as follows. (The extension of the result to a general finite-horizon setting is a somewhat elaborate application of backwards induction.) For the agents in a two-period version of our model, sequences of transfers have two key characteristics. The first is the net present value of the transfer sequence. The second is whether the transfers are relatively high in the first period (frontloaded), or in the second period (back-loaded). Because of their ability to secretly store, the agents in our model, ceteris paribus, prefer to have front-loaded transfer sequences; they can always use their storage technologies to smooth such sequences over time. But their willingness to substitute NPV for front-loading differs; in particular, agents with temporarily high incomes have a stronger relative preference for NPV as opposed to front-loading.

Because agents with temporarily high incomes have a stronger preference for NPV, it is not incentive-compatible for them to receive strictly less NPV than agents with temporarily low incomes. But, to obtain efficient risk-sharing, the planner wants to deliver more NPV to the agents with temporarily low incomes. Thus, the dictates of efficiency are in exact opposition to the dictates of incentive-compatibility. In a Pareto optimal allocation, the tension between efficient risksharing and incentive-compatibility is resolved by all agents ending up with the same NPV, and optimally smoothing that NPV over their lifetimes. This is equivalent to the agents' borrowing and lending among themselves using risk-free bonds.

Our results provide an explicit microfoundation for the incomplete markets structure assumed in a number of papers including Lucas (1980); Bewley (1993); Huggett (1993); Aiyagari (1994); Ríos-Rull (1994); Heaton and Lucas (1996); and Gomes, Greenwood, and Rebelo (1997)]. These papers study incomplete markets models in which a continuum of agents with idiosyncratic income shocks competitively trade a risk-free bond over time. Our 
paper also makes a methodological contribution. Fudenberg, Holmstrom, and Milgrom (1990) provide characterizations of efficient allocations in a wide class of dynamic environments such that agents' preferences over continuation contracts are common knowledge after any history. Ours is the first paper to our knowledge to provide a characterization of efficient allocations in an environment in which this property is not satisfied. Technically, the failure of this property makes our task challenging because efficient contracts are no longer Markov in continuation utilities.

The plan of the paper is as follows. In section 2 we lay out a finite horizon version of our environment. In section 3 we characterize efficient allocations. In section 4 we show that these efficient arrangements can be supported by trade in risk-free bonds. In section 5 we extend our results to versions of our model that include an infinite horizon, diminishing returns to storage, and lotteries. We also discuss how our main result can be reinterpreted as applying to an environment with hidden effort. In section 6 we conclude.

\section{Environment}

There is a continuum of identical agents who each live for $T$ periods. There is a single consumption good $c$ in every period. In period $n$, individual preferences over consumption streams are representable by the utility function

$$
E_{n} \sum_{t=n}^{T} \beta^{t-n} u\left(c_{t}\right)
$$

where we assume that $u(\cdot)$ is $C^{2}$ over $(0, \infty), u^{\prime}$ is positive, $u^{\prime \prime}$ is negative, and $\lim _{c \rightarrow 0} u^{\prime}(c)=$ $\infty$. The domain of $u$ is the entire real line; $u(c)=-\infty$ for $c<0$. We also assume that $u$ displays nonincreasing absolute risk aversion (NIARA) over $\Re_{+}$. This assumption implies that $u^{\prime}$ is strictly convex over this region.

In each period, an individual receives a storable unobservable stochastic endowment. We denote the realization of the endowment good in period $t$ by $\theta_{t}$, and we assume that it has finite support $Y=\left\{y_{1}, \ldots, y_{J}\right\}$ of nonnegative reals, where $y_{j}<y_{j+1}$. We assume that endowments are i.i.d. both across individuals and across time, and we denote the probability of an individual receiving endowment $y_{j}$ by $\pi\left(y_{j}\right)>0$. We assume that the gross return on storage of the endowment good is $R>0$ and that individuals can store goods in a private 
storage unit that is unobservable to others or in a public storage facility that is observable to all. As we shall see, the ability to store publicly does not improve societal welfare, but allowing for this possibility does make proving our results somewhat easier. While we generally restrict attention to the case where initial storage is zero, we later discuss how our results readily extended to the case where initial storage is positive.

This simple structure, with the exception of our finite-horizon assumption, corresponds to our notion of the classic dynamic income insurance structure with capital and growth. The specification of income shocks is what Green (1987) originally assumed. Unlike Green, we do not assume exponential utility with an unbounded consumption space, but instead use a preference class that nests power utility [as in Atkeson and Lucas (1992)] and assume that consumption is bounded from below. (Our results would extend to an environment with exponential utility and individual consumption sets that are unbounded from below.) Our storage technology is exactly the linear production structure that is assumed in much of the endogenous growth literature. ${ }^{2}$ We assume a finite horizon so that we can exposit our main ideas simply. In Section 5, we consider a number of extensions to our basic framework, including allowing the horizon to be infinite and allowing for a concave aggregate production function.

We use the following notation. We denote the history of shocks through period $t$ by

$$
\theta^{t} \equiv\left\{\theta_{1}, \ldots, \theta_{t}\right\}
$$

We denote the probability of a history $\theta^{t}$ by

$$
\pi\left(\theta^{t}\right) \equiv \prod_{n=1}^{t} \pi\left(\theta_{n}\right)
$$

We denote the set of possible histories in period $n$, given $\theta^{t}$ where $n \geq t$, by

$$
Y^{n}\left(\theta^{t}\right) \equiv\left\{\theta^{t}\right\} \times Y^{n-t}
$$

Given a history $\theta^{t}=\left(\theta_{1}, \ldots, \theta_{t}\right)$ of shocks realized through period $t$, we denote by $\theta^{n}\left(\theta^{t}\right) \equiv$ $\left(\theta_{1}, \theta_{2}, \ldots, \theta_{n}\right)$ the subhistory realized through period $n \leq t$, and we denote by $\theta_{n}\left(\theta^{t}\right)$ the shock in period $n \leq t$ implied by the history.

\footnotetext{
${ }^{2}$ See, for example, Jones and Manuelli (1990) and Rebelo (1991).
} 
In this setting, an allocation is a vector $\left(c_{t}, s_{t}, \tau_{t}, S_{t}\right)_{t=1}^{T}$, where

$$
\begin{aligned}
c_{t} & : \quad Y^{t} \rightarrow \Re \\
s_{t}: & Y^{t} \rightarrow \Re_{+} \\
\tau_{t} & : \quad Y^{t} \rightarrow \Re \\
S_{t} & \in \Re
\end{aligned}
$$

Here, $c_{t}\left(\theta^{t}\right)$ is the consumption of an individual who has history $\theta^{t} \in Y^{t}, s_{t}\left(\theta^{t}\right)$ is that individual's nonnegative private storage level, and $\tau_{t}\left(\theta^{t}\right)$ is the transfer of consumption that the individual receives (note that it can be negative). $S_{t}$ is the level of public storage undertaken by the society. Note that our notion of allocation immediately assumes that agents can only be distinguished through their histories. (Formally, an individual with history $\theta^{t}$ has endowment $\theta_{t}\left(\theta^{t}\right)$ and private savings level $s_{t-1}\left(\theta^{t-1}\left(\theta^{t}\right)\right)$ in period $t$; however, as long as no ambiguity is created by doing so, we will denote these values by $\theta_{t}$ and $s_{t-1}\left(\theta^{t-1}\right)$.)

An allocation is feasible if:

$$
\begin{aligned}
& \forall\left(t, \theta^{t}\right), c_{t}\left(\theta^{t}\right)+s_{t}\left(\theta^{t}\right) \leq R s_{t-1}\left(\theta^{t-1}\right)+\tau_{t}\left(\theta^{t}\right)+\theta_{t}, \\
& \forall t, S_{t}+\sum_{\theta^{t} \in Y^{t}} \pi\left(\theta^{t}\right) \tau_{t}\left(\theta^{t}\right) \leq R S_{t-1}, \\
& \forall t, S_{t} \geq 0 \\
& S_{0}=0, s_{0}=0 .
\end{aligned}
$$

Since both income realizations and private storage are unobservable, individuals can deviate from allocations in two ways. First, individuals can pretend to have different income histories, and thereby receive the transfer payments associated with that history. Second, individuals can choose different levels of storage. Let $\Sigma$ be the set of reporting and storage strategies $\left(\widehat{\theta}_{t}, \widehat{s}_{t}\right)_{t=1}^{T}$, where:

$$
\begin{aligned}
& \widehat{\theta}_{t}: Y^{t} \rightarrow Y \\
& \widehat{s}_{t}: Y^{t} \rightarrow \Re_{+}
\end{aligned}
$$


Let $\theta$ denote the truth-telling strategy in which $\hat{\theta}_{t}\left(\theta^{t}\right)=\theta_{t}$ for all $\left(t, \theta^{t}\right)$.

Given a transfer allocation $\tau$, an individual receives (ex-ante) utility $V(\widehat{\theta}, \widehat{s} ; \tau)$ from following reporting strategy $\widehat{\theta}$ and storage strategy $\widehat{s}$, where:

$$
\begin{aligned}
& V(\widehat{\theta}, \widehat{s} ; \tau) \equiv \sum_{t=1}^{T} \sum_{\theta^{t} \in Y^{t}} \beta^{t} \pi\left(\theta^{t}\right) u\left(\theta_{t}+R \widehat{s}_{t-1}\left(\theta^{t-1}\right)+\tau_{t}\left(\widehat{\theta}_{t}\left(\theta^{t}\right)\right)-\widehat{s}_{t}\left(\theta^{t}\right)\right) \\
& \text { given } \widehat{s}_{0}=0 \text {. }
\end{aligned}
$$

We say that an allocation $(c, s, \tau, S)$ is incentive-compatible if:

$$
V(\theta, s ; \tau) \geq \max _{(\widehat{\theta}, \widehat{s}) \in \Sigma} V(\widehat{\theta}, \widehat{s} ; \tau) .
$$

An allocation that is both incentive-compatible and feasible is said to be incentive-feasible. ${ }^{3}$

\section{Efficient Allocations}

Our goal in this paper is to characterize the efficient incentive-feasible allocations in this environment. Since all individuals are ex ante identical and we are restricting ourselves to symmetric allocations, these allocations will be the solution to the following problem:

$$
\begin{aligned}
& \mathbf{P 1}: \max _{(c, s, \tau, S)} \sum_{t=1}^{T} \sum_{\theta^{t} \in Y^{t}} \beta^{t-1} \pi\left(\theta^{t}\right) u\left(c_{t}\left(\theta^{t}\right)\right) \\
& \text { subject to } \\
& V(\theta, s ; \tau) \geq V(\widehat{\theta}, \widehat{s} ; \tau) \forall(\hat{\theta}, \hat{s}) \in \Sigma \\
& \forall\left(t, \theta^{t}\right), c_{t}\left(\theta^{t}\right)+s_{t}\left(\theta^{t}\right)=R s_{t-1}\left(\theta^{t-1}\right)+\tau_{t}\left(\theta^{t}\right)+\theta_{t} \\
& \forall t, S_{t}+\sum_{\theta^{t} \in Y^{t}} \pi\left(\theta^{t}\right) \tau_{t}\left(\theta^{t}\right) \leq R S_{t-1} \\
& \forall\left(t, \theta^{t}\right), s_{t}\left(\theta^{t}\right), S_{t} \geq 0 \\
& S_{0}=0, s_{0}=0
\end{aligned}
$$

In this problem, the first constraint requires that allocations be incentive-compatible; the other three constraints requires that the allocation be feasible. Clearly, there exists a solution to $\mathrm{P} 1$, because the constraint set is compact and the objective function is continuous.

\footnotetext{
${ }^{3}$ It is straightforward to show that an allocation is incentive-compatible (as defined here) if and only if it is the Nash equilibrium outcome of some anonymous mechanism. See Cole and Kocherlakota (1998) for further details.
} 
Because private storage and public storage have the same rate of return, there is no loss to having the planner do all of the storage publicly. This logic gives rise to the following proposition, which helps simplify problem P1.

Proposition 1. Given any incentive-feasible allocation $(c, s, \tau, S)$, there exists another incentivefeasible allocation $\left(c, 0, \tau^{\prime}, S^{\prime}\right)$.

Proof. Define $\tau_{t}^{\prime}\left(\theta^{t}\right)=\tau_{t}\left(\theta^{t}\right)-s_{t}\left(\theta^{t}\right)+R s_{t-1}\left(\theta^{t-1}\right)$ and $S_{t}^{\prime}=\sum_{\theta^{t}} \pi\left(\theta^{t}\right) s_{t}\left(\theta^{t}\right)+S_{t}$. We claim $\left(c, 0, \tau^{\prime}, S^{\prime}\right)$ is incentive-feasible. The feasibility is obvious. Suppose $\left(c, 0, \tau^{\prime}, S^{\prime}\right)$ is not incentive-compatible, and there exists $(\widehat{\theta}, \widehat{s})$ such that:

$$
V\left(\widehat{\theta}, \widehat{s} ; \tau^{\prime}\right)>V(\theta, 0 ; \tau)
$$

But then define the storage strategy: $s_{t}^{*}\left(\theta^{t}\right)=s_{t}\left(\widehat{\theta}^{t}\left(\theta^{t}\right)\right)+\widehat{s}_{t}\left(\theta^{t}\right)$ and note that (4) implies that $V\left(\widehat{\theta}, s^{*} ; \tau\right)>V(\theta, s ; \tau)$, which contradicts the incentive-compatibility of $(c, s, \tau, S)$.

\section{A. Characterizing Efficient Allocations}

In this section, we establish our main characterization of efficient allocations. It consists of two conditions on consumption allocations. A consumption allocation $c$ satisfies the consumption smoothing condition if:

$$
\begin{aligned}
& \forall t<T \text { and } \theta^{t}: \\
& u^{\prime}\left(c_{t}\left(\theta^{t}\right)\right)=\beta R \sum_{\theta_{t+1} \in Y} \pi\left(\theta_{t+1}\right) u^{\prime}\left(c_{t+1}\left(\theta^{t}, \theta_{t+1}\right)\right)
\end{aligned}
$$

A consumption allocation $c$ satisfies the net present value (NPV) condition if:

$$
\forall \theta^{T}, \sum_{t=1}^{T} R^{-t}\left(\theta_{t}\left(\theta^{T}\right)-c_{t}\left(\theta^{t}\left(\theta^{T}\right)\right)\right)=0
$$

Under this condition, the NPV of transfers, along any history $\theta^{T}$, is equal to zero since $S_{0}=s_{0}=0$. (Here and throughout the rest of the paper, the NPV of a transfer scheme is potentially stochastic, because it refers to the NPV of transfers along a given history.)

These two conditions would emerge from an environment in which individuals were choosing their consumption optimally given that they could only save and borrow at rate $R$. 
In the appendix, we demonstrate that there is a unique consumption allocation that satisfies the NPV and consumption-smoothing conditions (see section A1).

NOTATION: The symbol $c^{*}$ refers to the unique consumption allocation that satisfies consumption smoothing (5) and the NPV property (6).

We define $c^{*}$ to be feasible if there exists some feasible allocation $\left(c^{*}, s, \tau, S\right)$. It is possible that $c^{*}$ is not feasible, because it may imply that aggregate storage is negative in some date. In particular, it is straightforward to show that $c^{*}$ is feasible if and only if:

$$
\forall t, \sum_{\theta^{t} \in Y^{t}} \pi\left(\theta^{t}\right) \sum_{n=1}^{t} R^{t-n}\left(\theta_{n}\left(\theta^{t}\right)-c_{n}^{*}\left(\theta^{n}\left(\theta^{t}\right)\right)\right) \geq 0
$$

Later, we provide sufficient conditions on the exogenous parameters $(\beta, u, y, \pi)$ such that $c^{*}$ is feasible.

The main proposition that we prove in this section is:

If $c^{*}$ is feasible, then an incentive-feasible allocation $(c, s, \tau, S)$ is efficient (solves P1) if and only if $c=c^{*}$.

We prove this proposition using the following line of logic. First, we define P2, a programming problem with the same objective but a larger constraint set. Second, we demonstrate that an allocation solves P2 if and only if the consumption allocation $c=c^{*}$. Third, we establish that $c^{*}$ is incentive-feasible for $\mathrm{P} 1$ if $c^{*}$ satisfies our nonnegative condition (7). Hence, it follows that if this condition is satisfied, $c=c^{*}$ in any solution to P1. (The reason for the potential multiplicity of solutions to $\mathrm{P} 1$ is that there will typically be many incentive-feasible allocations which differ solely in their division of savings between that which is privately observable and that which is publicly observable.)

\section{B. The Relaxed Problem and Its Solution}

To define the relaxed problem P2, consider the following subset $\Sigma_{R}$ of the set of all reporting and storage strategies $\Sigma$. A strategy $(\widehat{\theta}, \widehat{s})$ is an element of $\Sigma_{R}$ if:

$$
\begin{aligned}
& \text { 1. }\left(\forall t<T, \forall \theta^{t-1}, j=2, \ldots, J\right), \widehat{\theta}_{t}\left(\theta^{t-1}, y_{j}\right) \in\left\{y_{j}, y_{j-1}\right\} \\
& \quad \widehat{\theta}_{t}\left(\theta^{t-1}, y_{j}\right)=y_{j-1} \text { or } \hat{s}_{t}\left(\theta^{t}\right) \neq 0 \Rightarrow \widehat{\theta}_{n}\left(\theta^{t-1}, y_{j}, \theta_{t}^{n}\right)=\theta_{n} \forall t<n \leq T, \\
& \text { 2. }\left(\forall t<T, \forall \theta^{t-1}\right), \widehat{\theta}_{t}\left(\theta^{t-1}, y_{1}\right)=y_{1},
\end{aligned}
$$




$$
3 \forall\left(t, \theta^{t}\right), \hat{s}_{t}\left(\theta^{t}\right) \geq 0 \text {. }
$$

The first restriction states that, in periods $t<T$, agents can either tell the truth or lie downwards by one notch in the grid of possible income realizations, and if an agent ever lies or stores, he must thereafter tell the truth. The second restriction says that if an agent has the lowest possible income realization, he can only tell the truth. There is no restriction on possible storage strategies beyond nonnegativity.

Given this definition of $\Sigma_{R}$, the relaxed problem P2 is constructed from P1 in three ways. First, we require private storage levels to be zero; from Proposition 1, we know that this does not affect the maximized value of the objective. Second, we allow $S_{t}$ to be nonnegative for $t<T$. Finally, we require agent strategies to lie in $\Sigma_{R}$; restricting the set of possible deviations from a given allocation expands the set of allocations that lie in the constraint set.

$$
\begin{gathered}
\text { P2: } \max _{(c, s, \tau, S)} \sum_{t=1}^{T} \sum_{\theta^{t} \in Y^{t}} \beta^{t-1} \pi\left(\theta^{t}\right) u\left(c_{t}\left(\theta^{t}\right)\right) \\
\text { subject to } \\
V(\theta, 0 ; \tau) \geq \max _{(\widehat{\theta}, \widehat{s}) \in \Sigma_{R}} V(\widehat{\theta}, \widehat{s} ; \tau) \\
\forall\left(t, \theta^{t}\right), c_{t}\left(\theta^{t}\right)=\tau_{t}\left(\theta^{t}\right)+\theta_{t} \\
\forall t, S_{t}+\sum_{\theta^{t} \in Y^{t}} \pi\left(\theta^{t}\right) \tau_{t}\left(\theta^{t}\right) \leq R S_{t-1} \\
S_{T} \geq 0 \\
S_{0}=0, s_{0}=0
\end{gathered}
$$

Note that by construction, if $(c, 0, \tau, S)$ solves $\mathrm{P} 2$, and $(c, 0, \tau, S)$ is incentive-feasible, then $(c, 0, \tau, S)$ solves P1. Clearly, there exists a solution to P2, because the constraint set is bounded and closed, and the objective function is continuous.

We now show that if an allocation $(c, 0, \tau, S)$ solves P2, $c$ must satisfy the consumptionsmoothing and NPV conditions.

Proposition 2. Let:

$$
\tau_{t}^{*}\left(\theta^{t}\right) \equiv c_{t}^{*}\left(\theta^{t}\right)-\theta_{t}\left(\theta^{t}\right)
$$




$$
S_{t}^{*} \equiv-\sum_{\theta^{t} \in Y^{t}} \pi\left(\theta^{t}\right) \sum_{n=1}^{t} R^{t-n} \tau_{n}^{*}\left(\theta^{n}\left(\theta^{t}\right)\right)
$$

The allocation $\left(c^{*}, 0, \tau^{*}, S^{*}\right)$ is the unique solution to PQ.

Proof. See the appendix.

We prove this proposition by showing that if $(c, 0, \tau, S)$ solves $\mathrm{P} 2$, then $c$ satisfies the consumption-smoothing condition (5) and the NPV condition (6). We do so using backwards induction. It is straightforward to show that if $(c, 0, \tau, S)$ satisfies the incentive constraints in P2, then it satisfies the consumption-smoothing and NPV conditions in period $T$. Then, we assume that an optimal $(c, 0, \tau, S)$ satisfies the consumption-smoothing and NPV conditions from period $t$ onwards ${ }^{4}$, and use this assumption to prove that the two conditions must also hold in period $(t-1)$.

The proof of consumption-smoothing in period $(t-1)$ is as follows. First, individuals can only be borrowing constrained,

$$
u^{\prime}\left(c_{t}\left(\theta^{t}\right)\right)>\beta R E_{\theta^{t}} u^{\prime}\left(c_{t+1}\left(\theta^{t+1}\right)\right)
$$

and not savings-constrained, where the inequality is reversed, since they can always privately store. Given this fact, we construct a better allocation by having the planner "borrow" at rate $R$ (reduce $S_{t}$ ) and then offer a loan to the constrained individual at his shadow interest rate. The shadow rate is higher than $R$, because the individual is borrowing-constrained, and so this generates extra resources for the planner. Because deviant strategies are restricted to lie in $\Sigma_{R}$, deviant individuals can only have more resources in the current period. We prove that because they have a lower shadow interest rate, such individuals are made worse off by the planner's loan.

Proving that the solution satisfies the NPV condition in period $(t-1)$ is more challenging. We note first that, given consumption-smoothing, any transfer scheme that gives an individual with a lower endowment shock a higher NPV sequence of transfers must lie outside the constraint set of P2 (because individuals with a high endowment shock will lie downward to get the high NPV transfer sequence). Then we show that if the NPV of the

\footnotetext{
${ }^{4} \mathrm{An}$ allocation satisfies the NPV condition from period $t$ onwards if $\sum_{n=t}^{T} R^{t-n}\left(\theta_{n}-c_{n}\left(\theta^{n}\right)\right)$ is independent of $\left(\theta_{t}, \ldots, \theta_{T}\right)$.
} 
transfer to an individual with a higher endowment shock is also higher, then the planner should shift resources from the agents with high realizations to those with low realizations. Because of risk aversion, this transfer uses fewer total resources but keeps ex ante utility the same. Finally, we prove that this change in plan reduces the welfare of deviant individuals. As it turns out, this is a direct consequence of NIARA.

\section{Equivalence of P2 and P1}

We have established a simple characterization of the solution to the relaxed problem P2: In any solution to P2, the consumption allocation equals $c^{*}$. This means that the agents receive the same NPV, regardless of what they report, and telling the truth is weakly optimal, because the planner optimally smooths a truth-telling agent's consumption stream. It follows that any solution to P2 is incentive-compatible. The only possible reason that a solution to P2 might not be incentive-feasible is that $c^{*}$ might not be feasible.

This logic is the basis for the following proposition.

Proposition 3. If $c^{*}$ is feasible, then an incentive-feasible allocation $(c, s, \tau, S)$ is efficient (solves P1) if and only if $c=c^{*}$.

Proof. See the appendix.

Note that the potential infeasibility of a solution to P2 only arises because we assume that our economy is closed. If we were to instead follow Green (1987) and assume that the basic environment was a small open economy, with the world interest rate equal to the net return on storage, then $c^{*}$ would automatically be feasible. It would follow from Proposition 3 that the consumption allocation in the solution set to P2 is also the allocation of consumption in the solution set to the small open economy version of P1.

There is only one solution $\left(c^{*}, 0, \tau^{*}, S^{*}\right)$ to P2. Proposition 1 guarantees that if $c^{*}$ is feasible, then $\left(c^{*}, 0, \tau^{*}, S^{*}\right)$ solves $\mathrm{P} 1$. However, there are many solutions to $\mathrm{P} 1$, because the aggregate storage can be split arbitrarily between public and private storage. Thus, there are many incentive-feasible allocations $\left(c^{*}, s, \tau, S\right)$, and they all solve $\mathrm{P} 1$.

The above characterization of efficiency applies only to environments in which the consumption allocation $c^{*}$ is feasible. The following proposition makes clear that there is a non-empty set of such environments. 
Proposition 4. The consumption allocation $c^{*}$ is feasible if either of the following two conditions is satisfied:
(i.) $R \geq \beta^{-1}$
(ii.) $y_{1}=0$.

Proof. See the appendix.

The proof for condition (i) works off the fact that if marginal utility is convex, then consumption smoothing implies that average consumption must be growing. The proof for condition (ii) is a direct consequence of the Inada condition on marginal utility and the NPV condition on transfers. If $c^{*}$ is infeasible, then some individual must have consumed more than his income in terms of NPV over the past $t$ periods. This means that the NPV of his future transfers must be negative, regardless of what endowments are actually realized. But this is impossible, because with positive probability, the individuals receive zero income in every future period.

Proposition 4 only establishes that a nonempty set of environments exists in which $c^{*}$ is feasible. When we use the theorem of the maximum, it is easy to see that for all $u, Y$, and $\pi$, there exists some $\beta^{*}<R^{-1}$ such that $c^{*}$ is feasible when $\beta \geq \beta^{*}$. Similarly, for all $u, \pi, \beta$, and $\left\{y_{2}, \ldots, y_{J}\right\}$, there exists $y_{1}^{*}>0$ such that if $y_{1} \geq y_{1}^{*}$, then $c^{*}$ is feasible. More generally, the key requirement to guaranteeing the feasibility of $c^{*}$ is that individuals need to be sufficiently willing to exchange current consumption for future consumption. This requirement can be generated in two ways: returns on storage that are close to the inverse of the discount factor or risky income streams that give rise to a significant precautionary savings demand.

In interpreting Proposition 4, it is worth noticing that the relationship between output and storage in our model is the same linear production technology assumed in much of the endogenous growth literature. If we relabel storage as capital, then it would seem only natural to assume that the return on capital, $R$, was in fact higher than $\beta^{-1}$ to ensure the capital stock growth without bound in equilibrium, regardless of the exogenously specified distribution of income. 


\section{Supporting the Efficient Arrangement}

We now consider the equilibrium outcomes of a dynamic incomplete markets economy embedded in our physical and informational environment. In this trading arrangement, individuals competitively trade consumption and risk-free one-period bonds that are available in zero net supply in each period. There is complete enforcement in this economy: individuals must pay off their debts in every state of the world, and they cannot end their lives in debt. We show if $c^{*}$ is feasible, the efficient consumption allocation $c^{*}$ is an equilibrium consumption allocation in the incomplete markets economy. Further, we prove that if there is an equilibrium in the incomplete markets economy such that the rate of return on bonds is in every period equal to the net rate of return on storage, then the allocation of consumption in that equilibrium is $c^{*}$. Finally, we show that if the equilibrium interest rate is in any period less than $(R-1)$, then the equilibrium allocation of consumption is inefficient.

The dynamic incomplete markets economy takes the following form. In each period, individuals trade consumption in exchange for risk-free bonds that promise one unit of consumption next period. The individuals treat interest rates (that is, the relative price between bonds and consumption in each period) as given. Individuals derive wealth in a given period from storage, from the interest payments on their bonds, and from their income. Individuals can use their wealth in three ways: they can store it, they can consume it, or they can use it to buy and sell bonds.

Hence, individuals choose consumption, bond holdings, and storage $\left\{c_{t}, b_{t}, s_{t}\right\}_{t=1}^{T}$, where each of the components of this vector is a function mapping $Y^{t}$ into the reals. Treating the interest rate sequence $\left\{r_{t}\right\}$ as fixed, the individuals make these choices so as to solve the following problem:

$$
\begin{aligned}
& \max E \sum_{t=1}^{T} \beta^{t} u\left(c_{t}\right) \\
& \text { subject to } \\
& c_{t}+b_{t}+s_{t} \leq \theta_{t}+b_{t-1}\left(1+r_{t}\right)+R s_{t-1} \\
& b_{T} \geq 0 \\
& s_{t} \geq 0
\end{aligned}
$$




$$
b_{0}=0, s_{0}=0
$$

An equilibrium in this economy is a sequence of interest rates $\left\{r_{t}\right\}$ and a solution $\left\{c_{t}, b_{t}, s_{t}\right\}_{t=1}^{T}$ to the individual's decision problem such that for $t=1, \ldots, T$,

$$
\begin{aligned}
& E\left\{b_{t}\right\}=0 \\
& E\left\{c_{t}\right\}+E\left\{s_{t}\right\}=R E\left\{s_{t-1}\right\}
\end{aligned}
$$

where $E$ represents the unconditional expectation of the random variable. Equation (9) requires that per capita bond holdings equal zero, and equation (10) requires that per capita demand and per capita supply are equated in the goods market.

Given this definition of equilibrium, we can prove the following proposition.

Proposition 5. If $c^{*}$ is feasible, then the efficient consumption allocation $c^{*}$ is a dynamic incomplete markets equilibrium allocation of consumption. In that equilibrium, $\left(1+r_{t}\right)=R$ for all $t$. Conversely, if $\left(1+r_{t}\right)=R$ for all $t$ in a dynamic incomplete markets equilibrium, then the equilibrium allocation of consumption equals $c^{*}$, and so is efficient.

Proof. See the appendix.

The first statement of Proposition 5 follows directly from the characterization of efficiency in Proposition 2, while the second statement follows from the observation that because $\left(1+r_{t}\right)=R$, the dynamic incomplete markets equilibrium allocation implies a transfer function that satisfies the consumption smoothing and NPV conditions.

Note that in the dynamic incomplete markets economy, storage could be public or private. Hence, when the efficient consumption allocation and the competitive equilibrium consumption allocation are the same, there is a solution to $\mathrm{P} 1$ with the same consumption allocation and only private storage. It follows that Proposition 5 also applies to an environment with no public storage. Note also that if storage was positive in each period $t<T$, then this would imply that $\left(1+r_{t}\right)=R$.

The following proposition proves that if the society faces a binding nonnegativity constraint on storage, then the equilibrium allocation is inefficient. 
Proposition 6. If in a dynamic incomplete markets equilibrium $\left(1+r_{t}\right)<R$ for some $t$, then the equilibrium allocation is inefficient.

Proof. See the appendix.

The proposition follows from the fact that when there is a gap between the equilibrium interest rate and the return on storage, then the planner can, in the efficient allocation, tax the high income individuals for the right to save and transfer these proceeds to the low income individuals in such a way as to raise ex ante welfare.

\section{Extensions and Generalizations}

In this section, we generalize our results along several dimensions. First, we show that in an infinite-horizon version of the above economy, if there exists some consumption allocation $c^{*}$ that is feasible and satisfies both the NPV and consumption-smoothing conditions, then any incentive-feasible allocation $\left(c^{*}, s, \tau, S\right)$ is efficient. This guarantees that if $\left(1+r_{t}\right)=R$ in a competitive equilibrium in the dynamic incomplete markets economy, then the equilibrium allocation is efficient. Next, we consider two variants of our model for which our results continue to apply: a hidden action version with an underground sector and a version in which the aggregate storage technology is concave. Next, we consider the robustness of our results to allowing society to use lotteries in the allocation of resources. Finally, we consider allowing for positive initial storage levels.

\section{A. Infinite Horizon}

For this subsection, we let $T=\infty$. We also add the assumptions that $u$ is bounded from above and below, $R>1$, and $y_{1}>0$. We impose these assumptions only because they are sufficient (albeit overly strong) to guarantee that there is some $c^{*}$ that satisfies the consumption-smoothing and NPV conditions [Sotomayor (1984)]. We define an infinite horizon analog of P2 by changing the terminal condition on $S_{T}$ to be:

$$
\lim _{T \rightarrow \infty} R^{-T} S_{T} \geq 0
$$

and setting the terminal date $T$ equal to infinity elsewhere in the problem.

We can then prove the following extension of our previous results. 
Proposition 7. Let:

$$
\begin{aligned}
\tau_{t}^{*}\left(\theta^{t}\right) & \equiv c_{t}^{*}\left(\theta^{t}\right)-\theta_{t}\left(\theta^{t}\right) \\
S_{t}^{*} & \equiv-\sum_{\theta^{t} \in Y^{t}} \pi\left(\theta^{t}\right) \sum_{n=1}^{t} R^{t-n} \tau_{n}^{*}\left(\theta^{n}\left(\theta^{t}\right)\right)
\end{aligned}
$$

The allocation $\left(c^{*}, 0, \tau^{*}, S^{*}\right)$ solves $\mathrm{P} 2$.

Proof. See the appendix.

A simple corollary to Proposition 7 is that if $c^{*}$ is feasible, then any incentive-feasible allocation $\left(c^{*}, s, \tau, S\right)$ is efficient. Using the proof of Proposition 5, we can then show that if in a dynamic incomplete markets competitive equilibrium $\left(1+r_{t}\right)=R$ for all $t$, then the equilibrium allocation is $c^{*}$, and so is efficient.

\section{B. Hidden Actions: A Reinterpretation}

In the environment discussed in the body of the paper, individual income is unobservable. To what extent does our main decentralization result carry over to environments in which the outcomes of at least some economic activities are observable, but the inputs are not? To address this question, we consider a simple variant of the model in which there are two sectors: one in which output is observable and one in which it is not. We assume that labor effort and productivity are unobservable in both sectors. We can interpret the observable sector as legal market production and the unobservable sector as either the underground economy or home production.

An example of the sort of model that we have in mind is as follows. Assume that individuals are endowed with a unit of time in each period that they can allocate to either of two sectors. Let $l_{t}$ denote an individual's labor effort in the legal sector in period $t$ and $1-l_{t}$ be the amount allocated to the unobserved sector. Let $z_{t}$ denote an individual's productivity in period $t$. This level of productivity is the same in each of the two sectors. Individuals' output in the observable sector is given by $z_{t} l_{t}$ in period $t$ and in the unobservable sector by $z_{t}\left(1-l_{t}\right)$. We assume that the distribution of $z_{t}$ is the same as $\theta_{t}$ in our unobservable-income model. In this model, adjusting $l_{t}$ works exactly like lying about the size of one's income shock. Furthermore, the efficient transfer scheme and the consumption allocation are exactly 
the same as in the original environment.

The extension to a hidden action model reinforces the point that expanding the space of unobservable activities individuals can undertake may reduce the complexity of efficient allocations, thereby allowing for more appealing decentralizations. Note that even though these additional hidden activities make the optimal arrangement simpler (and arguably more realistic), they nonetheless make individuals worse off ex ante (as long as the new hidden activities are not more productive than those available publicly).

\section{Diminishing Marginal Returns to Storage}

Assume, as in Aiyagari (1994), that the return to total storage at the aggregate level is given by the concave, continuous, and nonnegative function $R(\cdot)$, where $R(0)=0$ and $R^{\prime}(0)=\infty$. Assume that individuals can add private storage to the public amount and withdraw its proceeds without being detected.

If $\tilde{S}_{t}$ denotes the total level of private storage, then the per unit return in period $t+1$

on storing $\tilde{S}_{t}$ in period $t$ is $\left[R\left(S_{t}+\tilde{S}_{t}\right)-R\left(S_{t}\right)\right] / \tilde{S}_{t}$. We can show that given any feasible allocation, there is an equivalent zero private storage allocation, just as we did in Proposition 1. Given this, we can once again restrict attention to zero private storage allocation, and because individuals are infinitesimal, the per unit return on any individual who deviates and stores a positive amount is simply $R^{\prime}\left(S_{t}\right)$. We can then use this ability of the individual to store linearly at the same marginal rate as the planner to show, by essentially the same arguments we used in the proof of Proposition 2, that the solution to P2 will still satisfy our consumption smoothing condition and that the NPV of transfers is independent of an individual's reports. However, the NPV will not be zero, because the production technology exhibits decreasing returns to scale, and, hence, there will be positive profits associated with it. We can still establish that the solution to P2 is a solution to P1 by the same argument as before. Furthermore, any solution to P2 will exhibit nonnegative storage.

The solution to P2 can be decentralized if we assume that a price-taking firm operates the aggregate storage technology and that, at date 0 , the claims to the profits of the firm are distributed equally. Since in any competitive equilibrium the interest rate will satisfy $r_{t}=R^{\prime}\left(S_{t}\right)-1$, the associated allocation is efficient. 


\section{Lotteries}

We have thus far restricted ourselves to deterministic allocations, but this restriction is innocuous in our environment. Lotteries can potentially allow the planner to screen on the basis of risk, thereby achieving better outcomes. [See Cole (1989).] However, it is easy to show that our assumption that preferences exhibit NIARA implies that there is no gain from lotteries in this environment. The proof is similar to that of the NPV property in Proposition 2. To see this, note that if in period $T$, some type $\theta^{T-1}$ was receiving a random transfer, we could reduce the expected transfer while keeping this type's ex ante utility the same. By the same logic we used in the proof of Proposition 2, we can use our assumption of NIARA to prove that this would lower $E_{T-1} u^{\prime}\left(c_{T}\right)$ for this type, and, hence, no one would want to deviate under these new transfers if he didn't under the original transfers. We can then extend the result to previous periods by backward induction, just as we did in the proof.

Finally, lotteries do not allow us to obtain a simple decentralization where we otherwise could not. Prescott and Townsend (1984) propose a decentralization of environments with private information. However, in the environment considered by Green (1987), as well as in our environment with hidden income and hidden storage, Prescott and Townsend's (1984) decentralization simply assumes that there are competing firms who offer insurance contracts as of time zero, and the individuals can choose among the contracts. Hence, Prescott and Townsend's (1984) decentralization also cannot allow for trade in the sort of simple assets assumed in the incomplete markets literature.

\section{E. Nonzero Initial Storage}

We can easily allow for $S_{0}>0$. This would change our NPV condition to be a requirement that since the NPVs of the transfer all have to be equal, they have to equal the per capital level of initial public storage. Having positive initial public storage would expand the set of returns on storage $R$ and distributions of income $Y$ for which our results would go through. It would also enable us to relax the assumption that $y_{1}>0$ in proposition 7 , since what we need is either $y_{1}>0$ or $S_{0}>0$ in order to ensure that the marginal value of additional resources is finite in period 1. Finally, note that there is no distinction between positive initial public storage and positive initial private storage if these levels are common 
knowledge.

\section{Conclusion}

We consider an environment in which individuals have idiosyncratic income shocks. In this economy, there is a unique consumption allocation such that consumption is smoothed over time and the NPV of transfers received by individuals is independent of the shocks they experience. The main result in this paper is that if this unique allocation is physically feasible, then it is the only efficient allocation of consumption.

We use this characterization to show that the symmetric efficient allocation is decentralizable through a dynamic incomplete markets trading arrangement, in which individuals competitively trade risk-free bonds among themselves and face infinite costs of dying in debt. Thus, apparently ad hoc restrictions on the securities available for trade are consistent with the implementation of the efficient allocation in this setting. ${ }^{5}$

Our results are robust to several natural extensions of our basic model. If we simply reinterpret our environment as being a small open economy and assume that the exogenous world rate is equal to the return to storage, then the nonnegative storage condition is removed, and our results will hold for any nondegenerate income distribution. Our extension to a concave production technology makes clear that the assumption of a linear storage technology is made for expositional ease. Furthermore, as long as the marginal return to storage is high relative to the discount factor for low storage levels, our results will again hold for any nondegenerate income distribution. This assumption is satisfied by virtually all the production structures assumed in aggregate models.

Our results do, of course, depend on existence of hidden storage or hidden investment opportunities. However, this feature of the model seems easy to rationalize. Throughout history, people have hidden wealth using grain, gold, and jewelry, as well as foreign bank accounts, currency, and hard to observe assets within a business. Our results also depend upon the rate of return on hidden and public storage being equal. However, one can show

\footnotetext{
${ }^{5}$ Kehoe and Levine (1993) and Alvarez and Jermann (1997) discuss ways to decentralize efficient allocations in environments with enforcement frictions. These decentralizations require a complete set of securities combined with borrowing constraints. Hence, while enforcement frictions can explain limited risk-sharing, they cannot rationalize the elimination of income-contingent securities.
} 
that if the rate of return on private storage is not that different from that on public storage, simple debt contracts provide a good approximation to the efficient allocations. 


\section{Appendix}

In proving the various results, it will prove convenient to define the payoff to a finite horizon savings problem. Let $U(A, t)$ be defined as the solution to

$$
\text { (A1) P3:U(A,t) }=\max _{\left\{c_{n}\right\}} E\left\{\sum_{n=t}^{T} \beta^{n-t} u\left(c_{n}\left(\theta^{n}\right)\right) \mid \theta^{t-1}\right\}
$$

subject to

$$
\forall \theta^{T}, \sum_{t=n}^{T} R^{t-n}\left(\theta_{n}\left(\theta^{T}\right)-c_{n}\left(\theta^{n}\left(\theta^{T}\right)\right)\right) \leq A
$$

The function $U$ represents the maximal ex-ante utility that is feasible given that the agent is endowed with $A$ units of initial wealth, has $T-t+1$ periods remaining, and is free to borrow and lend, subject to the constraint that he cannot die in debt, regardless of what sequence of shocks afflicts him. Note that $U$ is increasing, is concave, and exhibits NIARA [Neave (1971)].

In what follows, we use the notation $P 3(A, t)$ to refer to the problem $P 3$ with initial wealth $A$ in period $t$.

\section{A1. Proof that $c^{*}$ is unique}

The problem $\mathrm{P} 3(A, t)$ defined in (A1) has a compact constraint set and a continuous objective function, it has a solution. Since the constraint set is convex and the objective function is strictly concave, it has a unique solution. And, furthermore, the first order conditions to this problem are both necessary and sufficient. Finally, note that for P3(0,1), the first order conditions consist of (5) and (6). Hence, $c^{*}$ is unique.

\section{A2. Proof of Proposition 2}

Before proving Proposition 2, we will find it useful to prove the following lemma about savings problems. To set up the lemma, let $\varepsilon, \delta>0$ satisfy $\varepsilon-\delta / R<0$. Then, define:

$$
\begin{aligned}
Z(y) & =\max _{s \geq 0} u(y-s)+\beta E_{z} v(z+R s), \\
W(y) & =\max _{s \geq 0} u(y-s+\varepsilon)+\beta E_{z} v(z+R s-\delta),
\end{aligned}
$$

where $v$ is a strictly concave function and $z$ is random second period income. 
Lemma 1. If $Z\left(y_{a}\right)=W\left(y_{a}\right)$, and $y_{b}>y_{a}$, then $Z\left(y_{b}\right)>W\left(y_{b}\right)$.

Proof. The proof is by contradiction. Define $s_{v}(y)$ and $s_{w}(y)$ to be the unique maximizers of the savings problems $Z$ and $W$ respectively. Standard arguments imply that they are weakly increasing.

Suppose that $W\left(y_{b}\right) \geq Z\left(y_{b}\right)$. Then by the Mean Value Theorem, there exists $y_{c} \in$ $\left(y_{a}, y_{b}\right)$ such that $W^{\prime}\left(y_{c}\right) \geq Z^{\prime}\left(y_{c}\right)$. This implies that:

$$
u^{\prime}\left(y_{c}+\varepsilon-s_{w}\left(y_{c}\right)\right) \geq u^{\prime}\left(y_{c}-s_{v}\left(y_{c}\right)\right) .
$$

The concavity of $u$ implies that

$$
0 \leq s_{v}\left(y_{c}\right) \leq s_{w}\left(y_{c}\right)-\varepsilon .
$$

The weak monotonicity of $s_{w}$ implies that $s_{w}\left(y_{b}\right) \geq s_{w}\left(y_{c}\right)$. But then we know that

$$
\begin{aligned}
Z\left(y_{b}\right) & \geq u\left(y_{b}+\varepsilon-s_{w}\left(y_{b}\right)\right)+\beta E v\left(z+R s_{w}\left(y_{b}\right)-\varepsilon R\right) \\
& >u\left(y_{b}+\varepsilon-s_{w}\left(y_{b}\right)\right)+\beta E v\left(z+R s_{w}\left(y_{b}\right)-\delta\right) \\
& =W\left(y_{b}\right)
\end{aligned}
$$

which is a contradiction.

Proof of Proposition 2. First, we prove that if $(c, 0, \tau, S)$ solves P2, then:

$$
\sum_{\theta^{t} \in Y^{t}} \tau_{t}\left(\theta^{t}\right) \pi\left(\theta^{t}\right)+S_{t}=R S_{t-1} \text { for all } t
$$

We do so by contradiction.

Suppose instead that this aggregate resource constraint does not hold with equality in period $t$. The planner should store the additional resources until period $T$ and give them to any individual who announces that he received the highest realization of the endowment good, $y_{J}$, in periods 1 through $T-1$. By the nature of the incentive constraints, no agent is allowed to claim that he got the highest shock if he did not; therefore, the incentive constraints can't be violated. Also, giving more consumption to agents in period $T$ will not lead them to save more. 
We next prove that for all $t$, the following is true of a solution $(c, 0, \tau, S)$ to $\mathrm{P} 2$ :

$$
\begin{aligned}
& \exists A_{t}: Y^{t-1} \rightarrow \Re \text { s.t. } \\
& A_{t}\left(\theta^{t-1}\right)=\sum_{n=t}^{T} \tau_{n}\left(\theta^{t-1}, \theta_{t-1}^{n}\right) R^{t-n} \\
& \left(c_{n}\left(\theta^{n}\right)\right)_{n=t}^{T} \text { solves } P 3\left(A_{t}\left(\theta^{t-1}\right), t\right)
\end{aligned}
$$

Here, the notation $\theta_{t-1}^{n}=\left(\theta_{t}, \theta_{t+1}, \ldots, \theta_{n}\right)$. Note that if $(\mathrm{A} 2)$ is true for $t=1$, then $c=c^{*}$.

We prove (A2) by backwards induction. Note first that it is true for $t=T$. The incentive constraints imply that for $t=T, \tau_{T}\left(\theta^{T}\right)$ is independent of $\theta_{T}$. Also, $c_{T}\left(\theta^{T}\right)=$ $\tau_{T}\left(\theta^{T}\right)+\theta_{T}$, and so it is trivially true that $c_{T}\left(\theta^{T}\right)$ solves $P 3\left(\tau_{T}\left(\theta^{T}\right), T\right)$.

Next, we make the inductive assumption that (A2) is valid for some $t$. Given this assumption, we prove that for all $\theta^{t-1}, u^{\prime}\left(c_{t-1}\left(\theta^{t-1}\right)\right)=\beta R \sum_{\theta \in Y} \pi(\theta) u^{\prime}\left(c_{t}\left(\theta^{t-1}, \theta_{t}\right)\right)$. The proof is by contradiction. Suppose that for some $\bar{\theta}^{t-1}$ :

$$
u^{\prime}\left(c_{t-1}\left(\bar{\theta}^{t-1}\right)\right)>\beta R \sum_{\theta \in Y} \pi(\theta) u^{\prime}\left(c_{t}\left(\bar{\theta}^{t-1}, \theta\right)\right) .
$$

(The reverse inequality is obviously inconsistent with the incentive constraints of P2.)

By the inductive assumption, the continuation payoff from period $t$ onwards is given by $U\left(A_{t}\left(\theta^{t-1}\right), t\right)$, where $U$ is defined in (A1) and $A_{t}\left(\theta^{t-1}\right)$ is defined in (A2). Set $\tilde{S}_{t-1}=$ $S_{t-1}-\varepsilon \pi\left(\bar{\theta}^{t-1}\right), \tilde{\tau}_{t-1}\left(\bar{\theta}^{t-1}\right)=\tau_{t-1}\left(\bar{\theta}^{t-1}\right)+\varepsilon$, and set $\left\{\tilde{\tau}_{n}\left(\bar{\theta}^{t-1}, \theta_{t-1}^{n}\right)\right\}_{n=t}^{T}$, and $\delta$ so that

$$
\begin{aligned}
& u\left(c_{t-1}\left(\bar{\theta}^{t-1}\right)+\varepsilon\right)+\beta U\left(A_{t}\left(\bar{\theta}^{t-1}\right)-\delta, t\right) \\
&= u\left(c_{t-1}\left(\bar{\theta}^{t-1}\right)\right)+\beta U\left(A_{t}\left(\bar{\theta}^{t-1}\right), t\right), \\
& u^{\prime}\left(c_{t-1}\left(\bar{\theta}^{t-1}\right)+\varepsilon\right) \geq \beta U\left(A_{t}\left(\bar{\theta}^{t-1}\right)-\delta, t\right),
\end{aligned}
$$

and

$$
\left\{\theta_{n}+\tilde{\tau}_{n}\left(\bar{\theta}^{t-1}, \theta_{t-1}^{n}\right)\right\}_{n=t}^{T} \text { is a solution to } \mathrm{P} 3\left(A_{t}\left(\bar{\theta}^{t-1}\right)-\delta, t\right) .
$$

By the envelope condition, $u^{\prime}\left(c_{t-1}\left(\bar{\theta}^{t-1}\right)\right)>\beta R \sum_{\theta \in Y} u^{\prime}\left(c_{t}\left(\bar{\theta}^{t-1}, \theta\right)\right)$ implies that $\delta>\varepsilon R$, and so this reshuffling is physically feasible and can be used to improve ex ante utility.

We still have to check the incentive constraints. To do so we want to show that the continuation payoff under $\tilde{\tau}$, conditional on reporting $\bar{\theta}^{t-1}$, is weakly less than $\tau$ for any $(\widehat{\theta}, \widehat{s}) \in$ 
$\Sigma_{R}$. If $\theta_{t-1}\left(\theta^{t-1}\right)=\bar{\theta}_{t-1}$ and $\hat{s}_{t-1}\left(\bar{\theta}^{t-1}\right)=0$, then the continuation payoff from deviating under $\tilde{\tau}$ is the same as under $\tau$. Hence the only relevant deviations involve $\theta_{t-1}\left(\bar{\theta}^{t-1}\right)>\bar{\theta}_{t-1}$ and/or $\hat{s}_{t-1}\left(\bar{\theta}^{t-1}\right)>0$. Then, if we set $\left.y_{a}=\bar{\theta}_{t-1}, y_{b}=\theta_{t-1}+s_{t-1}, z=\theta_{t}+R s_{t-1}\left(\bar{\theta}^{t-1}\right)+A_{t}\left(\theta^{t-1}\right)\right)$ and $v=U$, we can apply Lemma 1 to argue that if $\theta_{t-1}+s_{t-1}>\bar{\theta}_{t-1}$, the continuation payoff from deviating is less under $\tilde{\tau}$ then under $\tau$.

Thus, if $(c, 0, \tau, S)$ satisfies the inductive assumption and (A3), there exists $(\widetilde{c}, 0, \tilde{\tau}, \tilde{S})$ that satisfies the constraints of $\mathrm{P} 2$ and increases the objective over $(c, 0, \tau, S)$. It follows that the inductive assumption and the optimality of $(c, 0, \tau, S)$ implies that:

$$
u^{\prime}\left(c_{t-1}\left(\theta^{t-1}\right)\right)=\beta R \sum_{\theta \in Y} \pi(\theta) u^{\prime}\left(c_{t}\left(\theta^{t-1}, \theta\right)\right)
$$

for all $\theta^{t-1}$.

Next, we want to show that if consumption smoothing holds from period $t-1$ to period $t$, then this implies that $\tau_{t-1}\left(\theta^{t-1}\right)+R^{-1} A_{t}\left(\theta^{t-1}\right)$ is independent of $\theta_{t-1}$. Define $W_{j}\left(\theta^{t-2}\right)=$ $\tau_{t-1}\left(\theta^{t-2}, y_{j}\right)+R^{-1} A_{t}\left(\theta^{t-2}, y_{j}\right)$, which only depends only on $\theta^{t-2}$ and the current report $y_{j}$. We want to show that $W_{j}=W_{j-1}$ for all $j=2, \ldots, J$, and hence is independent of $j$.

Suppose that in a solution to P2, there exists $\bar{\theta}^{t-2}$ and $j>1$ such that $W_{j}\left(\bar{\theta}^{t-2}\right)<$ $W_{j-1}\left(\bar{\theta}^{t-2}\right)$. Consider an agent with actual history $\left(\bar{\theta}^{t-2}, y_{j}\right)$ who reports $\left(\bar{\theta}^{t-2}, y_{j-1}\right)$. This agent's nonnegative storage constraint does not bind in any future period, because an agent with lower income $y_{j-1}$ did not have a binding nonnegative storage constraint in the future. Hence, the lying agent receives continuation utility

$$
B\left(W_{j-1}\left(\bar{\theta}^{T-2}\right)+y_{j}\right) \equiv \max _{s} u\left(W_{j-1}\left(\bar{\theta}^{t-2}\right)+y_{j}-s\right)+\beta U(R s, t) .
$$

(Note that $U(W, t)$ in $\mathrm{P} 3$ is the ex ante version of $B$, and that similarly $B$ is increasing, is concave, and exhibits NIARA [Neave (1971)].) It follows that $W_{j}\left(\bar{\theta}^{t-2}\right)<W_{j-1}\left(\bar{\theta}^{t-2}\right)$ violates the incentive constraints in problem P2.

Now suppose that for some $\bar{\theta}^{t-2}$ and $j$,

$$
W_{j}\left(\bar{\theta}^{t-2}\right)>W_{j-1}\left(\bar{\theta}^{t-2}\right) .
$$

We claim that this cannot happen in a solution to P2, because there is a new transfer scheme that achieves the same ex ante utility by using fewer resources. Define $W_{C E}$ to be the wealth 
level such that:

$$
\begin{aligned}
& B\left(W_{C E}+y_{j}\right) \pi\left(y_{j}\right)+B\left(W_{C E}+y_{j-1}\right) \pi\left(y_{j-1}\right) \\
= & {\left[B\left(W_{j}\left(\bar{\theta}^{t-2}\right)+y_{j}\right) \pi\left(y_{j}\right)+B\left(W_{j-1}\left(\bar{\theta}^{t-2}\right)+y_{j-1}\right) \pi\left(y_{j-1}\right)\right] }
\end{aligned}
$$

Now, change the transfer scheme so that agents who announce $\left(\theta^{t-2}, y_{j}\right)$ or $\left(\theta^{t-2}, y_{j-1}\right)$ receive continuation utility $B\left(W_{C E}+y_{j}\right)$ or $B\left(W_{C E}+y_{j-1}\right)$ respectively. Clearly, this new mechanism frees up resources for the planner because of the concavity of $B$. Agent $j$ will not lie under the new mechanism. Agent $(j+1)$ will not lie, because the mechanism makes agent $j$ 's scheme less attractive.

We still need to check the incentive constraints from the previous periods. To do this, we need to show that the new mechanism does not increase the period $(t-1)$ continuation utility of any agent who has reported $\bar{\theta}^{t-2}$ and has stored $S$ (instead of 0$)$. The change in this agent's period $(t-1)$ continuation utility is given by:

$$
\begin{aligned}
\Delta(S)= & B\left(W_{C E}+y_{j}+S\right) \pi\left(y_{j}\right)+\pi\left(y_{j-1}\right) B\left(W_{C E}+y_{j-1}+S\right) \\
& -B\left(W_{j}\left(\bar{\theta}^{t-2}\right)+y_{j}+S\right) \pi\left(y_{j}\right)-\pi\left(y_{j-1}\right) B\left(W_{j-1}\left(\bar{\theta}^{t-2}\right)+y_{j-1}+S\right)
\end{aligned}
$$

We know that $\Delta(0)=0$. The derivative of $\Delta$ with respect to $S$ is:

$$
\begin{aligned}
\Delta^{\prime}(S)= & B^{\prime}\left(W_{C E}+y_{j}+S\right) \pi\left(y_{j}\right)+\pi\left(y_{j-1}\right) B^{\prime}\left(W_{C E}+y_{j-1}+S\right) \\
& -B^{\prime}\left(W_{j}\left(\bar{\theta}^{t-2}\right)+y_{j}+S\right) \pi\left(y_{j}\right)-\pi\left(y_{j-1}\right) B^{\prime}\left(W_{j-1}\left(\bar{\theta}^{t-2}\right)+y_{j-1}+S\right) \\
= & B^{\prime \prime}\left(X_{j}\right) \pi\left(y_{j}\right)\left(W_{C E}-W_{j}\left(\bar{\theta}^{t-2}\right)\right) \\
& +B^{\prime \prime}\left(X_{j-1}\right) \pi\left(y_{j-1}\right)\left(W_{C E}-W_{j-1}\left(\bar{\theta}^{t-2}\right)\right)
\end{aligned}
$$

where $X_{j} \in\left(W_{C E}+y_{j}+S, W_{j}\left(\bar{\theta}^{t-2}\right)+y_{j}+S\right)$ and $X_{j-1} \in\left(W_{j-1}\left(\bar{\theta}^{t-2}\right)+y_{j-1}+S, W_{C E}+\right.$ $\left.y_{j-1}+S\right)$.

Because $B$ satisfies $N I A R A, B^{\prime \prime}$ is an increasing function and $X_{j}>X_{j-1}$. Hence, we know that:

$$
\Delta^{\prime}(S)<\pi\left(y_{j}\right)\left(W_{C E}-W_{j}\left(\bar{\theta}^{t-2}\right)\right)+\pi\left(y_{j-1}\right)\left(W_{C E}-W_{j-1}\left(\bar{\theta}^{t-2}\right)\right)
$$




$$
<0
$$

for all $S$ and so $\Delta(S)<\Delta(0)=0$ for all $S$.

We have established that if $(c, 0, \tau, S)$ solves $\mathrm{P} 2$, and satisfies (A2) for some $t, u^{\prime}\left(c_{t-1}\right)=$

$\beta R E_{t-1} u^{\prime}\left(c_{t}\right)$ and $\sum_{n=t-1}^{T} \tau_{n}\left(\theta^{n}\right)$ is independent of $\theta_{t-1}^{T}$. It follows that $(c, 0, \tau, S)$ satisfies (A2) for $(t-1)$; by backwards induction, $(c, 0, \tau, S)$ satisfies (A2) for all $t$.

We have established that if $(c, 0, \tau, S)$ solves $\mathrm{P} 2$, then $c=c^{*}$. This immediately implies that if $\left(c^{*}, 0, \tau, S\right)$ lies in the constraint set of P2, it solves P2. Hence, an element $(c, 0, \tau, S)$ of the constraint set solves P2 iff $c=c^{*}$. It is easy to see that if $c=c^{*}$, then $S=S^{*}$ and $\tau=\tau^{*}$.

\section{A3. Proof of Proposition 3}

Let $\left(c^{*}, s, \tau, S\right)$ be an arbitrary feasible allocation. Because $c^{*}$ satisfies the consumptionsmoothing and NPV conditions, if an agent tells the truth, his consumption is optimally smoothed. Hence, agents weakly prefer to tell the truth and not store, and so $\left(c^{*}, s, \tau, S\right)$ is incentive-feasible. It follows from Proposition 1 that there exists $\left(c^{*}, 0, \tau^{\prime}, S^{\prime}\right)$ that is incentivefeasible. From Proposition 2, this allocation is a solution to P2, and so must be a solution to $\mathrm{P} 1$. It follows that $\left(c^{*}, s, \tau, S\right)$ is a solution to $\mathrm{P} 1$. The maximized values of $\mathrm{P} 1$ and $\mathrm{P} 2$ are the same.

Now suppose $(c, s, \tau, S)$ is some solution to $\mathrm{P} 1$ such that $c \neq c^{*}$. Again, from Proposition 1, there exists $\left(c, 0, \tau^{\prime}, S^{\prime}\right)$ that is a solution to P1. Because the maximized values of P1 and P2 are the same, $\left(c, 0, \tau^{\prime}, S^{\prime}\right)$ solves P2. But this violates Proposition 2.

\section{A4. Proof of Proposition 4}

We first prove condition (i). We know that in the unique solution to P2 consumption smoothing is satisfied. Hence,

$$
u^{\prime}\left(c_{t}\right)=\beta R E_{t} u^{\prime}\left(c_{t+1}\right)
$$

From the strict convexity of $u^{\prime}($.$) , it follows that E_{t} u^{\prime}\left(c_{t+1}\right) \geq u^{\prime}\left(E_{t} c_{t+1}\right)$. This implies that for all $\theta^{t}$,

$$
u^{\prime}\left(c_{t}\left(\theta^{t}\right)\right) \geq \beta R E_{\theta^{t}} u^{\prime}\left(c_{t}\left(\theta^{t+1}\right)\right) \geq u^{\prime}\left(E_{\theta^{t}} c_{t+1}\left(\theta^{t+1}\right)\right)
$$


and, in turn, it follows that

$$
\sum_{\theta^{T} \in Y^{T}}\left[c_{t+1}\left(\theta^{t}\left(\theta^{T}\right)\right)-c_{t}\left(\theta^{t}\left(\theta^{T}\right)\right)\right] \pi\left(\theta^{T}\right) \geq 0
$$

which implies that $S_{t} \geq 0$, because we know from Proposition 2 that the resource constraints hold with equality. This completes the proof of (i).

We next prove condition (ii). After any history $\theta^{t}, \operatorname{Pr}\left(\theta_{n}=0\right.$ for all $\left.n>t \mid \theta^{t}\right)>0$. Moreover, whenever $\theta_{n}=0$, then $\tau_{n}\left(\theta^{n}\right) \geq 0$. It follows that after any history $\theta^{t}$,

$$
\sum_{n=1}^{t} R^{n} \tau_{n}\left(\theta^{n}\left(\theta^{t}\right)\right) \geq 0 .
$$

This immediately implies that storage levels associated with any solution to P2 must be nonnegative because $u^{\prime}(0)=\infty$. This completes the proof of condition (ii).

\section{A5. Proof of Proposition 5}

To prove the first statement, consider a solution to P2 which satisfies the nonnegative storage condition, and recursively define

$$
\begin{aligned}
& r_{t}=R-1 \\
& s_{t}=S_{t} \\
& b_{t}\left(\theta^{t}\right)=\theta_{t}-c_{t}\left(\theta^{t}\right)-S_{t}+R S_{t-1}+b_{t-1}\left(\theta^{t-1}\left(\theta^{t}\right)\right) R .
\end{aligned}
$$

We claim that this is an equilibrium. To see that the bond market clears, note that if we make use of the individual's resource constraint in equation (1), this implies that

$$
E b_{t}=E\left\{\tau_{t}-S_{t}+R S_{t-1}+b_{t-1} R\right\}
$$

which, along with the resource constraint and nonnegative storage, implies that $E\left\{\tau_{t}-S_{t}+\right.$ $\left.R S_{t-1}\right\}=0$, and this implies the result, because $b_{0}=0$. To verify that individuals are behaving optimally, note that the interest rate has been chosen so that the individuals are indifferent between lending and storing. We also know that consumption is smoothed; therefore, we need only check that the individuals' budget constraints hold with equality. To see that the individuals' budget constraints are satisfied, note that

$$
b_{T}=-\tau_{T}+R S_{T-1}+R b_{T-1}
$$




$$
\begin{aligned}
= & -\tau_{T}-R \tau_{T-1}+R^{2} S_{T-2}+R^{2} b_{T-2} \\
& \vdots \\
= & -\sum_{n=0}^{T-1} R^{n} \tau_{T-n} \\
= & 0 .
\end{aligned}
$$

To prove the second statement, construct a transfer/storage scheme by defining $\tau_{t} \equiv$ $\theta_{t}-c_{t}$ and defining $S_{t}$ to be per capita storage (both public and private) in equilibrium. This scheme must be an element of P2's constraint set, because the NPV of the difference between income and consumption must be zero in the equilibrium. Moreover, given that $R=\left(1+r_{t}\right)$, the consumption smoothing condition is satisfied, and so this scheme must be a solution to P2. It is also a solution to P1, because aggregate storage is nonnegative. Thus, the corresponding equilibrium allocation of consumption is efficient.

\section{A6. Proof of Proposition 6}

To prove the proposition we show that if $1+r_{t} \neq R$, then there exists a Pareto superior incentive-feasible allocation. To do so, consider an equilibrium of the dynamic incomplete markets economy, $\left\{c_{t}, b_{t}, s_{t}, r_{t}\right\}$, where in period $n, 1+r_{n}>R$. As in the proof of proposition 6 , we can construct an associated incentive feasible allocation in which the consumption allocation is the same as our incomplete markets economy and private storage is zero, by defining $\tau_{t} \equiv \theta_{t}-c_{t}$ and defining $S_{t}$ to be per capita storage. We denote this associated incentive-feasible allocation by $\left(c_{t}, 0, \tau_{t}, S_{t}\right)$. For some $\bar{\theta}^{n-1} \in Y^{n-1}$ and $1<j \leq J$, consider altering the consumption allocation (and correspondingly the transfer scheme) in period $n$ by setting $\tilde{c}_{n}\left(\theta^{n-1}, y_{j}\right)=c_{n}\left(\theta^{n-1}, y_{j}\right)-\varepsilon$, where $y_{j}-y_{j-1}>\varepsilon>0$, and choosing $\delta(\varepsilon)$, where $\tilde{c}_{n}\left(\theta^{n-1}, y_{j-1}\right)=c_{n}\left(\theta^{n-1}, y_{j-1}\right)+\delta(\varepsilon)$, so that ex ante utility is unchanged, or

$$
E \sum_{t=n}^{T} \beta^{t-n} u\left(\tilde{c}_{t}\left(\bar{\theta}^{n-1}, \theta_{n}^{t}\right)\right)=E \sum_{t=n}^{T} \beta^{t-n} u\left(c_{t}\left(\bar{\theta}^{n-1}, \theta_{n}^{t}\right)\right) .
$$

For $\varepsilon$ sufficiently small: 
1. Since individuals strictly prefer to tell the truth under $\tilde{\tau}$, the individual who has income $y_{j}$ in period $n$ has no incentive to misreport his income, or

$$
\begin{aligned}
& u\left(\tilde{c}_{t}\left(\bar{\theta}^{n-1}, y_{j}\right)\right)+E \sum_{t=n+1}^{T} \beta^{t-n} u\left(\tilde{c}_{t}\left(\bar{\theta}^{n-1}, y_{j}, \theta_{n+1}^{t}\right)>\right. \\
& u\left(y_{j}+\tilde{\tau}_{n}\left(\bar{\theta}^{n-1}, y_{j-1}\right)-s_{n}\right)+ \\
& \max _{\{\hat{\theta}, s\}}\left[\begin{array}{c}
E \sum_{t=n+1}^{T} \beta^{t-n} u\left(\theta_{t}+\tau_{t}\left(\bar{\theta}^{n-1}, y_{j-1}, \hat{\theta}_{t}\left(\theta_{n+1}^{t}\right)\right)-s_{t}\left(\theta_{n+1}^{t}\right)+R s_{t-1}\left(\theta_{n+1}^{t}\right)\right)
\end{array}\right] .
\end{aligned}
$$

2. Since $\delta^{\prime}>0$ and $\delta(0)=0$, and individuals strictly preferred not to store in period $n$ under the initial allocation, the individual who has income $y_{j-1}$ in period $n$ still has no incentive to store, or

$$
u^{\prime}\left(\tilde{c}_{t}\left(\bar{\theta}^{n-1}, y_{j-1}\right)\right)<R \beta E_{\theta_{n+1}} u^{\prime}\left(\tilde{c}_{t}\left(\bar{\theta}^{n-1}, y_{j-1}, \theta_{n+1}\right)\right)
$$

3. Again making use the strictness of the incentive constraints and the properties of $\delta$, the individual who has income $y_{j-2}$ has no incentive to misreport his income, or

$$
\begin{gathered}
u\left(\tilde{c}_{t}\left(\bar{\theta}^{n-1}, y_{j-2}\right)\right)+E \sum_{t=n+1}^{T} \beta^{t-n} u\left(\tilde{c}_{t}\left(\bar{\theta}^{n-1}, y_{j-2}, \theta_{n+1}^{t}\right)>\right. \\
u\left(y_{j-2}+\tilde{\tau}_{n}\left(\bar{\theta}^{n-1}, y_{j}\right)-s_{n}\right)+ \\
\max _{\{\hat{\theta}, s\}}\left[\begin{array}{c}
E \sum_{t=n+1}^{T} \beta^{t-n} u\left(\theta_{t}+\tau_{t}\left(\bar{\theta}^{n-1}, y_{j}, \hat{\theta}_{t}\left(\theta_{n+1}^{t}\right)\right)-s_{t}\left(\theta_{n+1}^{t}\right)+R s_{t-1}\left(\theta_{n+1}^{t}\right)\right)
\end{array}\right] .
\end{gathered}
$$

4. Individuals have no incentive to save between periods $n-1$ and $n$, since

$$
\begin{aligned}
E u^{\prime}\left(c_{t}\left(\bar{\theta}^{n-1}, \theta_{n}^{t}\right)-E u^{\prime}\left(\tilde{c}_{t}\left(\bar{\theta}^{n-1}, \theta_{n}^{t}\right)\right)=\right. & \pi\left(y_{j}\right)\left[u^{\prime}\left(c_{n}\left(\bar{\theta}^{n-1}, y_{j}\right)\right)-u^{\prime}\left(c_{n}\left(\bar{\theta}^{n-1}, y_{j}\right)-\varepsilon\right)\right] \\
& +\pi\left(y_{j-1}\right)\left[u^{\prime}\left(c_{n}\left(\bar{\theta}^{n-1}, y_{j-1}\right)\right)-u^{\prime}\left(c_{n}\left(\bar{\theta}^{n-1}, y_{j-1}\right)+\delta\right)\right] \\
\simeq & -\pi\left(y_{j}\right) u^{\prime \prime}\left(c_{n}\left(\bar{\theta}^{n-1}, y_{j}\right)\right) \varepsilon+\pi\left(y_{j-1}\right) u^{\prime \prime}\left(c_{n}\left(\bar{\theta}^{n-1}, y_{j-1}\right)\right) \delta \\
< & 0
\end{aligned}
$$

from the convexity of $u^{\prime}$.

Since

$$
u\left(c_{t}\left(\bar{\theta}^{n-1}, y_{j}\right)\right)<u\left(\tilde{c}_{t}\left(\bar{\theta}^{n-1}, y_{j}\right)\right)<u\left(\tilde{c}_{t}\left(\bar{\theta}^{n-1}, y_{j-1}\right)\right)<u\left(c_{t}\left(\bar{\theta}^{n-1}, y_{j-1}\right)\right)
$$


$\varepsilon>\delta(\varepsilon)$, and the resource constraint is relaxed. It's fairly straightforward to allocate these additional resources in a way that doesn't violate the incentive constraints and raises ex ante utility since all of the incentive constraints still hold strictly.

\section{A7. Proof of Proposition 7}

We consider two alternative economies in which income uncertainty dies out after some period $T$ with either the highest or the lowest possible income. The payoff from the efficient arrangement in our infinite horizon economy (in which income uncertainty persists) is bracketed by the payoffs of the efficient arrangement in these two income risk truncated economies. We show that the solutions to P2 in these truncated economies satisfy the consumptionsmoothing and NPV conditions. By increasing the truncation period $T$, we squeeze the solution to P2 in the infinite horizon economy between these two allocations that satisfy the consumption-smoothing and NPV conditions. We show that this implies the solution to P2 in the infinite horizon economy must also satisfy the consumption-smoothing and NPV conditions.

Define $V_{\infty}^{\text {opt }}$ to be the supremal ex-ante utility derived from the allocations in the constraint set of P2. Consider two truncated versions of the infinite-horizon environment. In the first truncated environment, in period $t>T$, all agents receive the highest income level, $y_{J}$. In the second truncated environment, the planner is endowed with $S_{0}$ units of storage at the beginning of time, and in period $t>T$, all agents receive the lowest income level, $y_{1}$. We call the first environment $H_{T}$ and the second environment $L_{T}\left(S_{0}\right)$. Define $V_{H_{T}}$ to be the supremal ex ante utility derived from allocations that satisfy the constraints of P2 in environment $H_{T}$. Define $V_{L_{T}}\left(S_{0}\right)$ to be the supremal ex ante utility derived from allocations that satisfy the constraints of $\mathrm{P} 2$ in environment $L_{T}\left(S_{0}\right)$. Let $c_{L_{T}\left(S_{0}\right)}^{*}$ be the unique consumption allocation in $L_{T}\left(S_{0}\right)$ that satisfies consumption-smoothing and NPV conditions (the existence of such an allocation is guaranteed by our assumptions that $u$ is bounded, $R>1$, and $y_{1}>0$ ).

Part 1: We first want to show that any solution to P2 in environment $L_{T}\left(S_{0}\right)$ is the same as $c_{L_{T}}^{*}\left(S_{0}\right)$. The key to establishing this result is to demonstrate that in any solution to P2, consumption is smoothed from period $t$ to period $(t+1), t \geq T$, and $\tau_{T}\left(\theta^{T}\right)+R^{-1} N P V\left(\theta^{T}\right)$ is independent of $\theta_{T}$, where $N P V\left(\theta^{T}\right)$ is the NPV of the transfers received from period 
$(T+1)$ onward by an individual with reporting history $\theta^{T}$. Once we establish these claims, it is straightforward apply the backward induction arguments in the proof of Proposition 2 to prove that any solution to P2 in environment $L_{T}\left(S_{0}\right)$ satisfies the consumption-smoothing and NPV conditions.

We prove first that consumption-smoothing is satisfied for any solution to P2 for $t \geq T$. Note that in any allocation, $c_{t}$, for $t \geq T$, depends only on $\theta^{T}$. Suppose first that consumption is not smoothed from period $t$ to period $(t+1)$ for some agent with a history of reports $\theta^{T}$. Then the planner can raise consumption in period $t$ by $\delta$ and lower consumption in period $(t+1)$ by $\varepsilon(\delta)$ so as to leave the agent's utility

$$
u\left(c_{t}\left(\theta^{T}\right)+\delta\right)+\beta u\left(c_{t+1}\left(\theta^{T}\right)-\varepsilon(\delta)\right)=u\left(c_{t}\left(\theta^{T}\right)\right)+\beta u\left(c_{t+1}\left(\theta^{T}\right)\right)
$$

unchanged. If $\delta$ is sufficiently small, $\delta<R^{-1} \varepsilon(\delta)$; therefore, this new plan gives the planner extra resources. By arguments similar to those made in the proof of Proposition 2, we know that this change in the consumption plan will not lead an individual to deviate. Because we have found a plan that is incentive-feasible and leaves the planner with more resources, the allocation without consumption smoothing after period $T$ is not a solution to P2.

By using arguments similar to those in proposition 2 , we can now prove that $\tau_{T}\left(\theta^{T-1}, y_{j}\right)+$ $R^{-1} N P V\left(\theta^{T-1}, y_{j}\right)=\tau_{T}\left(\theta^{T-1}, y_{j-1}\right)+R^{-1} N P V\left(\theta^{T-1}, y_{j-1}\right)$ for all $j$. But then applying the same backward induction argument as in Proposition 2 implies that $\left(c_{L_{T}\left(S_{0}\right)}^{*}, 0, \tau, S\right)$ solves P2 in environment $L_{T}\left(S_{0}\right)$.

Part 2 : We know that

$$
V_{H_{T}} \geq V_{\infty}^{o p t} \geq U\left(c^{*}\right) \geq V_{L_{T}}(0)
$$

If we can prove that as $T$ goes to infinity, $\left(V_{H_{T}}-V_{L_{T}}(0)\right)$ converges to 0 , we will know that $\left(c^{*}, 0, \tau, S\right)$ solves P2. The rest of the proof consists of proving this.

Let $c_{t, L_{T}\left(S_{0}\right)}^{*}$ denote the period $t$ component of the unique consumption allocation that satisfies the consumption-smoothing and NPV conditions in $L_{T}\left(S_{0}\right)$. We claim that

$$
c_{1, L_{T}\left(S_{0}\right)}^{*}\left(y_{j}\right) \geq c_{1, L_{T-1}\left(S_{0}\right)}^{*}\left(y_{j}\right) \text { for all } j .
$$

Suppose this claim is false. Then $c_{1, L_{T}\left(S_{0}\right)}^{*}\left(y_{j}\right)<c_{1, L_{T-1}\left(S_{0}\right)}^{*}\left(y_{j}\right)$ for some $j$. But from the consumption smoothing condition, $c_{2, L_{T}\left(S_{0}\right)}^{*}\left(y_{j}, y_{i}\right)<c_{2, L}^{*}\left(y_{j}, y_{i}\right)$ for some $y_{i}$. Similarly, there 
exists a history $\theta^{T}$ such that for all $t$,

$$
c_{t, L_{T}\left(S_{0}\right)}^{*}\left(\theta^{t}\left(\theta^{T}\right)\right)<c_{t, L_{T-1}\left(S_{0}\right)}^{*}\left(\theta^{t}\left(\theta^{T}\right)\right) .
$$

This violates the NPV restriction, because for any history, the NPV is higher in environment $T$ than in environment $(T-1)$.

This means that $V_{L_{T}}^{\prime}(0) \leq V_{L_{1}}^{\prime}(0)$ for all $T$. Now define $S_{0 T}=R^{-T}\left(y_{J}-y_{1}\right) /(R-1)$, and note that

$$
V_{L_{T}}\left(S_{0 T}\right) \geq V_{H_{T}}
$$

because the planner can replicate any allocation in $H_{T}$ if endowed with this much initial storage. Hence,

$$
\begin{aligned}
V_{H_{T}}-V_{L_{T}}(0) & \leq V_{L_{T}}\left(S_{0 T}\right)-V_{L_{T}}(0) \\
& \leq V_{L_{T}}^{\prime}(0) S_{0 T} \\
& \leq V_{L_{1}}^{\prime}(0) S_{0 T} .
\end{aligned}
$$

Because $S_{0 T}$ converges to 0 as $T$ goes to infinity, the proposition is proved. 


\section{References}

[1] Aiyagari, S. Rao. "Uninsured Idiosyncratic Risk and Aggregate Saving." Quarterly Journal of Economics 109 (August 1994): 659-684.

[2] Aiyagari, S. Rao, and Fernando Alvarez. "Stationary Efficient Distributions With Private Information and Monitoring: A Tale of Kings and Slaves." Manuscript, Federal Reserve Bank of Minneapolis, 1995.

[3] Allen, Franklin. "Repeated Principal-Agent Relationships With Lending and Borrowing." Economic Letters 17 (January 1985): 27-31.

[4] Alvarez, Fernando, and Urban Jermann. "Asset Pricing When Risk Sharing Is Limited by Default." Manuscript, University of Chicago, 1997.

[5] Atkeson, Andrew. "International Lending With Moral Hazard and Risk of Repudiation." Econometrica 59 (July 1991): 1069-1089.

[6] Atkeson, Andrew, and Robert E. Lucas, Jr. "On Efficient Distribution With Private Information." Review of Economic Studies 59 (July 1992): 427-453.

[7] Atkeson, Andrew, and Robert E. Lucas, Jr. "Efficiency and Equality in a Simple Model of Efficient Unemployment Insurance." Journal of Economic Theory 66 (June 1995): $64-88$.

[8] Bewley, Truman F. "Thoughts on Volatility Tests of the Intertemporal Asset Pricing Model." In Robert Becker, Michele Boldrin, Ronald Jones, and William Thomson, eds., General Equilibrium, Growth, and Trade. Volume 2. The Legacy of Lionel McKenzie, pp. 302-330. San Diego: Academic Press, 1993. 
[9] Cole, Harold L.. "Comment: General Competitive Analysis in an Economy With Private Information." International Economic Review 30 (February 1989): 249-252.

[10] Cole, Harold L. and Narayana Kocherlakota. "Efficient Allocations With Hidden Income and Hidden Storage," Federal Reserve Bank of Minneapolis Staff Report 238 (May 1998).

[11] Fudenberg, Drew, Bengt Holmstrom, and Paul Milgrom. "Short-Term Contracts and Long-Term Agency Relationships." Journal of Economic Theory 51 (June 1990): 1-31.

[12] Gomes, Joao, Jeremy Greenwood, and Sergio Rebelo. "Equilibrium Unemployment." Manuscript, University of Rochester, 1997.

[13] Green, Edward J. "Lending and the Smoothing of Uninsurable Income." In Edward C. Prescott and Neil Wallace, eds., Contractual Arrangements for Intertemporal Trade, pp. 3-25. Minneapolis: University of Minnesota Press, 1987.

[14] Green, Edward J., and Soo-Nam Oh. "Contracts, Constraints and Consumption." Review of Economic Studies 58 (October 1991): 883-899.

[15] Heaton, John, and Deborah J. Lucas. "Evaluating the Effects of Incomplete Markets on Risk Sharing and Asset Pricing." Journal of Political Economy 104 (June 1996): $443-487$.

[16] Hubbard, R. Glenn, Jonathan Skinner, and Stephen P. Zeldes. "Precautionary Saving and Social Insurance." Journal of Political Economy 103 (April 1995): 360-399.

[17] Huggett, Mark. "The Risk-Free Rate in Heterogeneous-Agent Incomplete-Insurance Economies." Journal of Economic Dynamics and Control 17 (September-November 1993): 953-969. 
[18] Jones, Larry E., and Rodolfo E. Manuelli. "A Convex Model of Equilibrium Growth: Theory and Implications." Journal of Political Economy 98 (October 1990): 1008-1038.

[19] Kehoe, Timothy J., and David K. Levine. "Debt-Constrained Asset Markets." Review of Economic Studies 60 (October 1993): 865-888.

[20] Khan, Aubik, and B. Ravikumar. "Growth and Distribution With Private Information." Manuscript, University of Virginia, 1997.

[21] Lucas, Robert E., Jr. "Equilibrium in a Pure Currency Economy." Economic Inquiry 18 (April 1980): 203-220.

[22] Marcet, Albert, and Ramon Marimon. "Communication, Commitment, and Growth." Journal of Economic Theory 58 (December 1992): 219-249.

[23] Neave, Edwin H. "Multiperiod Consumption-Investment Decisions and Risk Preference." Journal of Economic Theory 3 (March 1971): 40-53.

[24] Phelan, Christopher. "Repeated Moral Hazard and One-Sided Commitment." Journal of Economic Theory 66 (August 1995): 488-506.

[25] Phelan, Christopher, and Robert M. Townsend. "Computing Multi-Period, Information Constrained Optima." Review of Economic Studies 58 (October 1991): 853-881.

[26] Prescott, Edward C., and Robert M. Townsend. "General Competitive Analysis in an Economy With Private Information." International Economic Review 25 (February 1984): $1-20$.

[27] Rebelo, Sergio. "Long-Run Policy Analysis and Long-Run Growth." Journal of Political Economy 99 (June 1991): 500-521. 
[28] Ríos-Rull, José-Victor. "On the Quantitative Importance of Market Completeness." Journal of Monetary Economics 34 (December 1994): 463-496.

[29] Sotomayor, Marilda A. "On Income Fluctuations and Capital Gains." Journal of Economic Theory 32 (February 1984): 14-32.

[30] Spear, Stephen E., and Sanjay Srivastava. "On Repeated Moral Hazard With Discounting." Review of Economic Studies 54, (October 1987), pages 599-617.

[31] Taub, Bart. "Dynamic Mechanisms on a Continuum." Manuscript, University of Illinois, 1990.

[32] Thomas, Jonathan, and Tim Worrall. "Income Fluctuation and Asymmetric Information: An Example of a Repeated Principal-Agent Problem." Journal of Economic Theory 51 (August 1990): 367-390.

[33] Townsend, Robert M. "Optimal Multiperiod Contracts and the Gain From Enduring Relationships Under Private Information." Journal of Political Economy 90 (December 1982): 1166-1186.

[34] Wang, Cheng. "Dynamic Insurance With Private Information and Balanced Budgets." Review of Economic Studies 62 (October 1995), 577-595. 